\title{
EXENCIÓN DE RESPONSABILIDAD Y PERMANENCIA POR EL AUXILIO DE LA VÍCTIMA EN LA PERSECUCIÓN DE LAS REDES DE PROSTITUCIÓN CON INMIGRANTES: PROBLEMAS E INSUFICIENCIAS.
}

JOAQUÍN MARÍA RIVERA ÁLVAREZ

ANDRÉS ARIAS ASTRAY

E.U. Trabajo social. Universidad Complutense. Madrid.

Vendrán más años malos Y nos harán más ciegos; Vendrán más años ciegos Y nos harán más malos. R. Sánchez Ferlosio

\section{INTRODUCCIÓN.}

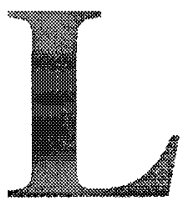

a presente comunicación tiene por objeto hacer una crítica al art. 59 de la Ley 4/2000, de 11 de enero como medida dentro del sistema abolicionista que actualmente predomina en España. ${ }^{1}$

Esta norma plantea una exención de la responsabilidad frente a la entrada y permanencia ilegal del inmigrante en España por su colaboración contra redes organizadoras de tráfico de personas -específicamente, nos centramos en el "Trafico de blancas"- ${ }^{2}$ Situación que no se agota en dicha exención sino que posibilita, a opción del inmigrante, el retorno a su país de procedencia o la estancia y residencia en España, así como el permiso de trabajo y las facilidades para su integración social. El artículo pretende la colaboración, mediante denuncia a las autoridades competentes, de los autores o cooperadores de dicho tráfico, o la cooperación o colaboración con los funcionarios policiales "proporcionando datos esenciales o testificando, en su caso, en el proceso correspondiente contra aquellos autores".

1 Cfr Garrido Guzman, L., La prostitución: estudio jurídico y criminologico, Edersa, Madrid 1992, pag.55 a 65.

2 Ya, con carácter discrecional, se facultaba como motivo humanitario la posibilidad de autorizar la estancia a las víctimas de las redes de tráfico ilegal de extranjeros, a partir del carácter genérico del art. 38.4 del Reglamento de Extranjería (RD 155/1996, de 2 de 


\section{II. ÁMBITO NORMATIVO DE LA APLICACIÓN DE LA EXEN- CIÓN.}

De una interpretación finalista del art. 59 de la Ley de Extranjería podría deducirse que se pretende utilizar la exención sólo ante los casos en donde se pueda imputar a los responsables de la red en un delito relativo a la prostitución con inmigrantes que hayan entrado bajo las condiciones de prevalimiento por la edad o capacidad, engaño, situación de necesidad o vulnerabilidad. Es decir, se habla de los autores o cómplices de una de las conductas del art. 187.2 y 3 del CP -prostitución de menores o incapaces $-^{3}$ o de la prostitución de mayores de edad capaces del art. 188.2 del CP -que plantea específicamente el problema de los inmigrantes- ${ }^{4}$.

Es evidente que, vistos la multitud de casos en nuestros tribunales, se puede causar también incidentalmente uno de detención ilegal o el de lesiones o malos tratos a las víctimas. ${ }^{5}$ Sin embargo, el propio enga-

febrero, por el que se aprobó el Reglamento de ejecución de la anterior Ley Orgánica 7/ 85) y Dictamen sobre el Proyecto de 5 de julio de 1995 del Consejo Económico y Social.

3 Así, en la Sentencia de 6 de febrero de 1998 (Aranz.- 942), una guineana menor de edad, junto con otras mayores, ejercía la prostitución en Zaragoza en 1995.

4 Caso que se plantea en la Sentencia de 6 de abril de 2000 del Tribunal Supremo (Aranz.3704 ) en donde, bajo el engaño de un trabajo como bailarina o modelo, se traían chicas brasileñas para obligarlas a alternar y prostituirse, planteado en el año 1997. Parecido supuesto, respecto a ciudadanas dominicanas en el caso contemplado en el Auto del Tribunal Supremo de 19 de enero del 2000 (Aranz.- 96); mediante la promesa de trabajo en labores domésticas o camareras en el año 1997; otro caso de colombianas, se retenía su pasaporte y se las amenazaba de causar un mal a su familia en Colombia y con sanciones económicas en la Sentencia de 15 de febrero de 1999 (Aranz.- 1168) en Oviedo en 1994-1995; un supuesto de una ciudadana checa, en donde se abusó de su juventud, desconocimiento del idioma, ausencia de amistades, situación ilegal para determinarla a la prostitución, sin remuneración alguna en Tenerife en 1997, tal como se ve en la Sentencia de 3 de febero de 1999 (Aranz.- 216); otro caso de checas en Castellón en 1995, en la Sentencia de 5 de octubre de 1998 (Aranz.- 6858) -si bien, en este caso, no se entró en la detención ilegal a pesar de no permitírseles salir y permanecer encerradas-.

5 Véase, en relación a la concurrencia del delito de determinación de la prostitución con lesiones y detención ilegal, el caso de la Sentencia del Tribunal Supremo de 23 de septiembre de 2000 (Aranz.- 9509), inducción a la prostitución de un grupo de húngaras, engañadas inicialmente mediante la promesa de la obtención de trabajo, cuando llegan a España son controladas por la organización en pisos tutelados y presionadas económicamente, amenazadas y lesionadas cuando no muestran su conformidad con el acceso carnal con clientes, en 1997. En la Sentencia del Tribunal Supremo de 26 de noviembre de 1999 (Aranz.- 8895), para un supuesto de ciudadanas panameñas y ucranianas que, bajo promesa de servir de camareras o trabajadoras en un hotel, las trajo a España, retirándoles el dinero y pasaje de avión y les dispuso a la prostitución previa amenaza, malos tratos y reclusión en el prostíbulo bajo llave y vigilancia de febrero a abril de 1994. En un caso de rusas idéntico al visto en $1997 \mathrm{en} \mathrm{Torremolinos,} \mathrm{véase} \mathrm{el} \mathrm{Auto} \mathrm{del}$ Tribunal Supremo de 11 de mayo de 1999 (Aranza.- 6676). Idéntico supuesto en Jaén en 1991, la Sentencia del Tribunal Supremo de 2 de junio de 1999 (Aranz.- 5455), si bien 
ño, la situación de necesidad o superioridad o vulnerabilidad, serán determinantes para la aplicación de la exención vistas éstas «de modo personal e individualizable como situación concreta de algo determinado, no prescindible sin grave perjuicio físico o moral, o la presencia de una especial indefensión y en términos tales que limite en verdad la objetiva capacidad de libre autodeterminación sexual en el necesita$\mathrm{do}^{6}>$. Parecería conveniente que debe operar la medida, una vez condenados los miembros de la organización, para evitar las denuncias infundadas ${ }^{7}$, sin embargo, por la virtualidad abolicionista de nuestro sistema, en casos de falta de condena, a pesar de la prueba de la realidad del abuso, convendría ser más flexibles, así como preocuparse de conceder la estancia del sujeto en interés de la justicia.

\section{CRÍTICA A LA MEDIDA DE POLÍTICA CRIMINAL.}

Inicialmente, deberíamos mostrarnos conformes con dicha medida, al considerar que la norma procura "intensificar las acciones y medidas legales contra las mafias de traficantes de seres humanos, manteniendo la posibilidad además de incentivar a través del mecanismo previsto en este artículo, la colaboración con las autoridades por parte de los extranjeros víctimas de esta actividad ${ }^{8}$. Por otro lado, opera como una medida aparentemente beneficiosa para la víctima, ya que le permite la opción del retorno o de la estancia, con permiso de residencia y trabajo; incluso con posterioridad a la resolución de su expulsión del territorio y a la propia ejecución de la orden a partir de la intervención del Ministerio Fiscal (art. 59.3). También se busca la seguridad de las medidas de protección de testigos de la Ley 19/94, de 1994, que van desde la salvaguarda de su identidad, a la de su domicilio y futuro lugar de trabajo, la facilitación de documentos nuevos de identidad y medios económicos para cambiar de domicilio y lugar de trabajo en el art. 59.4, plenamente aplicable al supuesto? .

desde la perspectiva de la coacción de menores, con ciudadanas portuguesas que bajo amenaza y, en ocasiones, detención ilegal, ejercían la prostitución.

- De León Villalba, «Lna nota sobre la prostitución y la trata de blancas», en Rodríguez Yague, A.-Valmaña Ochaita S., La mujer como victima: Aspectos jurídicos y criminológicos, Universidad de Castilla La Mancha, Cuenca 2000, pag. 108. También para ver la realidad en Madrid, en cuanto a la determinación Barahona Gomariz, $\mathrm{M}^{\mathrm{a}} \mathrm{J}$, Tipología de la prostitución femenina en la Comunidad de Madrid, Dirección General de la Mujer (CAM), Madrid 2001, pags. 171 y ss.

7 Huertas González, R., "Comentario al art. 58», en Santaolaya Machetti, P., Comentarios a la nueva Ley de Extranjería, Ed- Lex Nova, Valladolid 2000, pag. 288.

8 Campo Cabal, "Comentario al art. 59. Colaboración contra redes organizadas", en Campo Cabal (Coord.), Comentarios a la Ley de Extranjería", Ed. Civitas, $1^{\circ}$ ed., Madrid 2001, pag.444. 
Ahora bien, sin perjuicio de poner en duda los riesgos y el efectivo cumplimiento de estas medidas de seguridad para la inmigración ilegal de prostitutas, por el alto coste que supone individualizarlas -fuera de las casas de acogida-, ${ }^{10}$ cabe plantearse otras posibles desventajas:

1. A la vista de los casos de nuestros Tribunales y del tenor del art. 59, la eficacia de tales medidas obra a partir de la intervención policial o judicial. Es decir, se trata de una medida reparadora. Es más, difícilmente, sin la existencia de un Servicio Social especializado que procure a la víctima la información de tales medidas -sin perjuicio de las acciones que pueden arbitrarse por las organizaciones internacionales- ésta intervendrá en el proceso como actora. Si vemos la realidad, sólo a partir de la agravación de la situación vital de la víctima es cuando acude a las autoridades, cuando se ve sin percibir remuneración alguna, privada de libertad ambulatoria totalmente, o maltratada de modo reiterado, normalmente después de un intento de liberación. Y lo hace casi siempre inducida por otra persona, en general alguno de los clientes habituales o mujeres de su entorno, víctimas o no. ${ }^{11}$ Por todo ello, se duda de la real eficacia de la medida, sobre todo midiendo el riesgo de enfrentarse de nuevo mediante su declaración ante, primero, el juez de instrucción $y$, después el juez o tribunal sentenciador, al proxeneta o al tercero que presta el local y su organización. ${ }^{12}$

2. Dentro de la línea reparadora, consideramos insuficiente la opción legislativa. Es decir, además del retorno a la residencia y trabajo,

9 Huertas González, R., Ob.cit., pag. 289.

10 En la Sentencia de 23 de septiembre del 2000 (Aranz.- 9509) se ve un caso de determinación con violencia e intimidación a un grupo de húngaras mayores de edad, en donde la propia acusada propinó una paliza a la testigo protegida, por la que sufrió condena por lesiones, con independencia del tipo específico de la prostitución.

11 Un caso reciente es el de un grupo de exprostitutas ejercientes en Madrid que interpuso una denuncia ante la Brigada de Extranjería contra los proxenetas que las explotaban. En unos casos recibieron la ayuda de las ONG's que operan en la Casa de Campo, quienes las remitieron a la policía. En otros, en cambio, consiguieron escapar por sus propios medios de los clubes en donde trabajaban o con la ayuda de algún cliente que las ayudó a llegar a la Comisaría. En total cerca de 100 mujeres, que habían entrado irregularmente cn España, se han acogido durante el último año a la Ley de Protección de Testigos y a la Ley de Extranjería. No obstante, el $90 \%$ de las testigos protegidas desconocía en el momento de interponer la denuncia que su situación podía regularizarse si colaboraba en la desmatelación de las redes a las que habían pertenecido. (Hidalgo, M. "La policía desmontó 20 redes de prostitutas en Madrid gracias a 'testigos protegidos' inmigrantes. La Morada. (http://www.la-morada.com/redesprostitutas.htm (10 de enero de 2002). Por su parte, el diario El País de 16 de junio de 2001 informaba que la policía tenía constancia de que al menos 30 mujeres, la mayoría rumanas que ejercían la prostitución en la Casa de Campo, habían denunciado a las redes que las introdujeron en España y la explotaban. Asimismo indicaba que la Policía Nacional había detenido al menos a 39 individuos acusados de proxenetismo, con el desmantelamiento de una organización rumana dedicada al tráfico de mujeres y a su explotación sexual en Madrid. 
deben operar medidas efectivas de inserción de la prostituta-víctima. El retorno no es siempre fácil, a partir de la estigmatización que se puede producir por el ejercicio de la prostitución o la situación de conflicto social que fue determinante de su inmigración o el sentimiento de fracaso que supone la "vuelta a casa" sin consecuciones económicas o personales. ${ }^{13}$ De esta manera debemos ofrecer previamente a la víctima un entorno para que se recupere de las secuelas psíquicas y físicas que le haya producido el ejercicio bajo las condiciones vistas de la prostitución, después es correcto plantearse el retorno o la estancia.

3. Son necesarias medidas orientadas a modificar las actitudes y comportamientos de los posibles clientes hacia la prostitución (y de forma más genérica ante la mujer) enfatizando, a la par, las consecuencias que se derivan de su utilización o consumo como sujetocosa. Esto es, adoptar la perspectiva de la política de responsabilización de la población, creando la conciencia de que quien utiliza

12 El testimonio de la víctima debe llevarse al momento del juicio oral, sin perjuicio de las posibilidades de la prueba anticipada, que debe procurarse en todo caso llegar a la fase de instrucción. Así se ve cómo operan como pruebas anticipadas ante el Juzgado de Instrucción de los testimonios de victimas que retornaron a su país en la Sentencia del Tribunal Supremo de 6 de abril de 2000 (Aranz.- 3704) y en la de 5 de Octubre de 1998 (Aranz.6858 ). Desde el punto de vista procesal, hay que atender a la exigencia de que la declaración prestada ante la autoridad judicial tenga la debida contradicción -presencia e intervención de los letrados de la acusación y defensa y el Ministerio Fiscal- y no haya sido posible encontrar al testigo, después de gestiones que resulten infructuosas, para que acuda al Juicio Oral (Sentencia del T.S. de 26 de noviembre de 1999 (Aranz.- 8895), y sca lcída conforme al art. 730 de la Lecrim en el juicio oral (Véase como paradigmática la Sentencia de 25 de abril del 2000, Aranz.- 6355).

13 Dos perspectivas feministas deseamos considerar: Una a través de Shrage, L, Moral dilemmas of feminism, prostitution, adultery and abortion, Routledge, Nueva York 1994, pag. X, pone en boca de Margo St James la idea de que "pensar que vender $-\mathrm{y}$ permitir la venta- de comerciar con el cuerpo degrada a las mujeres, es entrar en los estándares sexistas de doble moralidad que reduce a la mujer a la abstinencia sexual y al sacrificio propio del amor sexual" (Iraducción libre de los autores). Frente a esta opinión la autora, afortunadamente entiende, a través del examen histórico, que la prostitución tiene diferentes orígenes y consecuencias sociales, de forma que cuando por la misma se jerarquiza la sociedad es cuando es necesario políticas sociales que desnaturalicen o cambicn estas perspectivas.

La segunda línea se ve en Pheterson, G., El prisma de la prostitución, Ed. Talasa, Madrid 2000, pag. 123 y ss. que trabaja sobre la idea de cómo en determinadas sociedades, a consecuencia del rol de las mujeres, cuando tratan de mejorar su condición de vida, se ven atacadas externamente por un rechazo social e internamente por los condicionamientos previos de conducta aprendidos - caso del Islam-, de forma que cuando les llega la explotación sexual, difícilmente se logra recuperar su dignidad cuando previamente han resultado estigmatizadas y la "caída" en la prostitución es el efecto derivado. Así nos dice en la pag. 127: "La etiqueta de prostituta tiene más que ver con la transgresión como mujer de los códigos de género discriminatorios que con el comercio sexual real. Ya sea por desplazarse de manera independiente, por tener iniciativa cconómica o una determinada forma de vestir o desarrollar una actividad política, la trasgresión de los roles femeninos tradicionales ha sido llamado prostitución... Una vez marcada como prostituta la vuInerabilidad de una mujer hacia el abuso, la exclusión y la cxplotación se intentan justificar por su carácter y conducta supuestamente inmorales". 
la prostitución es uno de los agentes responsables más importantes de la degradación en la que se ve sumida esta población indefensa. En definitiva, se trataría de conseguir que el uso de la prostitución y no su ejercicio sea lo que se transforme en un problema social del mismo rango o importancia que aquéllos que más nos inquietan. Y ello por que es curioso la similitud, desde la perspectiva sociológica de dicha actitud, del consumidor, denominada "coexistencial", con los casos de maltrato en donde el maltratador también, con independencia de la voluntad y disposición de la víctima, se proporciona placer, utilizando la violencia, la superioridad física y otras circunstancias. ${ }^{14}$ Resulta en este punto grotesco indicar que el consumidor difícilmente conoce cuándo la prostituta está en condiciones de ejercicio de la "libertad sexual", pues difícilmente puede predicarse ésta en el comercio sexual. Aquí convendría tal vez decir, como Wassyla Tamzali15 que "aceptar la prostitución como principio de vida es aceptar las relaciones de dominación sexual". No obstante, retornamos a la cómoda y neutral silla a que nos aboga nuestro legislador y algunos otros tratadistas penales, sobre la base de la intervención mínima y fragmentaria propia de su ordenamiento. ${ }^{16}$

Por una parte, se debe superar la política de seguridad y de higiene públicas que, inclusive, se plantea actualmente en nuestras ciudades. Tampoco es un remedio la legalización de la prostitución como oficio, ni el retorno a los sitios cerrados y protegidos -curioso "ritornello" después de la Convención de 1950-.

Por otra parte, es necesario subrayar la limitación que en la práctica se impone al cumplimiento de alguna de las medidas que se derivan del artículo que venimos comentando, dado el tipo y el escaso número de dispositivos y servicios socioasistenciales especializados existentes para la atención a las prostitutas y exprostitutas. Para empezar, las

14 Cfr. Martín López, E., Familia y Sociedad. Una introducción a la sociología de la familia, RIALP, Madrid 2000, pag. 35-38. Shrage, Ob. Cit. pag. IX.

is Ob. Cit., pag. 32.

16 Cfr. De León Villalba, Ob. Cit., pag. 101 y ss. Así en la pag. 102 declara: «La constatación de una progresiva aceptación de comportamientos sexuales desde el prisma de la libertad de elección entre personas adultas, restringiendo su reproche a comportamicntos sexuales contrarios a la libertad personal y, en definitiva, el juego del principio de intervención mínima plasmada en la idea de que no es misión del Estado tutelar moralmente a los ciudadanos, sino garantizar las condiciones necesarias para la convivencia en libertad, y su colorario de que el aparato represivo del Estado no debe estar al servicio de lo que moralmente puede ser considerado como lo más acertado por un grupo, sino de lo que socialmente es necesario para posibilitar esa convivencia, sancionando los comportamientos más graves, ha llevado al legislador a despenalizar en el vigente Código Penal de 1995, conductas tradicionalmente típicas, relacionadas con la prostitución de mayores de edad (terceria locativa, proxenitismo, etc.) y a limitar la sanción penal a la prostitución penal de menores e incapaces...». 
Leyes de Servicios Sociales, salvo excepciones como la de Murcia (art. 44 b) Ley 8/1985, de 9 diciembre), no se refieren explícitamente a las prostitutas como colectivo susceptible de atención especializada. Esto ha provocado que no existan equipamientos especializados de titularidad pública para ayudar a solventar este peculiar tipo de problemática. Bien es cierto que las prostitutas se pueden beneficiar de ciertas prestaciones y servicios en función de otras problemáticas que las aquejen, como pueden ser la definida por el genérico término de exclusión social, por la drogadicción, por ser mujeres, etc. No obstante, el ejercicio de la prostitución impide el acceso a ciertas prestaciones como puede ser el $\mathrm{IMI}^{17}$ y cuando lo permite aparece situada en el último lugar de los grupos de atención preferente entre los tipos de perceptores que se benefician del mismo. ${ }^{18}$

El peso de la intervención social con las prostitutas se ha dejado, por lo tanto, en manos de la iniciativa privada. Algo, en un principio, no criticable, pero siempre sujeto a las modificaciones presupuestarias a las que suelen estar sometidos los capítulos de subvenciones. En la ciudad de Madrid, por ejemplo, destaca especialmente el trabajo realizado por Médicos del Mundo. Esta organización ha editado, con la colaboración del Ayuntamiento de Madrid, una guía de los recursos existentes para la atención a las prostitutas ${ }^{19}$ en el ámbito madrileño. Al consultarla sorprende el pequeño número de entidades que se dedican de forma específica a trabajar con este colectivo, en concreto, seis $^{20}$, siendo el resto de los recursos susceptibles de utilización motivada por otro tipo de problemática (drogadicción, enfermedad, etc.). Entre los servicios que ofrecen, se pueden destacar, entre otros: centros integrales de atención, pisos tutelados, talleres laborales, formación escolar, unidades móviles, proyectos de atención en los lugares en los que se ejerce la prostitución, asesoría jurídica, psicológica y social, reparto de preservativos, talleres de ocio y tiempo libre, escuela de madres, habilidades sociales, educación para la salud, atención sanitaria, líneas telefónicas de atención y sensibilización.

Concluyendo, es necesario el reforzamiento de la idea de dignidad de la mujer en este campo de la prostitución. Para eso, conviene comenzar a separar lo que es el honor y la moral, en su aspecto sexual, de

17 Tómense como ejemplo en este sentido el art. 24.4 de la Ley $1 / 1999$, de 5 febrero, por el que se modifica la Ley 9/1991, de 2 de octubre, de medidas básicas para la inserción social de Galicia.

18 Véase, en concreto, la Resolución, de 5 febrero 2001, relativa al Plan General de Inserción para 2001.

19 Médicos del Mundo y Ayuntamiento de Madrid. Recursos sociales y sanitarios para la atención a las personas que ejercen la prostitución, Ayuntamiento de Madrid, Madrid. 1998.

20 APRAMP, Cáritas, HETARIA, IPSSE, Médicos del Mundo y Villa Teresita. 
la dignidad, por cuanto ésta opera internamente en el sujeto humano, haciendo que el individuo cobre una alta consideración de sí mismo, sentimiento independiente de la consideración de los demás. Esta estima de uno permite el desarrollo del sujeto hacia una estabilidad emocional y hacia un enriquecimiento personal que es obstaculizado si se ve atacada su dignidad. Y sin duda vivir de la prostitución no es una experiencia enriquecedora, sino desintegradora de la propia estima. Este aspecto ha sido poco cuidado por los tratadistas, influenciados por la llamada revolución sexual de los años sesenta y, es más, se ha deteriorado nuestra perspectiva por el poder de los «mass media» y de los medios económicos que han trivializado los aspectos de dignidad y libertad en el hombre para hacer de ello un producto de consumo; especialmente la industria del sexo genera un muy alto beneficio a empresarios, aparentemente respetables -desde la perspectiva de la neutralidad moral de nuestra sociedad-. A esto se une la idea de que el fuero interno de la persona es intocable por el Estado, "por encima de los principios que no son acordes con la aspiración al bienestar, bien sean principios religiosos, políticos o de cualquier índole ${ }^{21}$ ".

Conviene, no obstante, preguntarse ¿hasta qué punto parece una ficción jurídica hablar de libertad sexual cuando la persona que se encuentra prostituyéndose no tiene suficientes «agarres personales» para considerarse digna? ?2; ¿ es posible seguir dando ese prurito de respetabilidad -legalidad - a una industria que ataca frontalmente la dignidad de las mujeres, esclavizándolas y considerándolas objeto de satisfacción del ciudadano? No se trata de reconducir el debate al Derecho Penal -cuyo carácter fragmentario imposibilita la punición de las conductas menos lesivas a la dignidad humana-, sino utilizar otras ramas del Ordenamiento, Derecho Administrativo y de los Servicios Sociales para llevar a la conciencia social la idea de que la prostitución es un grave ataque a la dignidad de la mujer, de modo que sirva esta consideración para una verdadera política social que trate de limitar el tráfico sexual a los menores casos posibles.

21 Candido, Que es la dignidad, Ed. Martinez Roca, Barcelona 2001, pag. 125. Continua el autor: " Por descontado que las leyes han ido adaptándose a esa situación, creando su lógica después de que la situación se haya impuesta. Primero es la situación desbordante, y luego la lógica que lo argumenta. La adaptación suele ser vertiginosa, como bien lo prueba la receptividad de las leyes en lo tocante a la regulación del aborto, actualmente en fase de supuestos. La única resistencia de las leyes, que en síntesis es la resistencia del Estado, nace de la obligación civil. De la misma manera que la enseñanza pública no está en el Estado confesional para hacer primordialmente buenos católicos, sino buenos ciudadanos, la reducción del aborto a unos supuestos concretos es una acción inducida de amparo a ciudadanos futuros".

22 Así la linea marcada por el pensamiento de Tamzali, W., De la necesidad de un debate sobre la prostitución en Europa, Madrid 1999, Dirección General de la Mujer (CAM), pag. 13. 